\title{
PEAK OXYGEN UPTAKE IN ARM ERGOMETRY: EFFECTS OF TESTING PROTOCOL
}

\author{
R. WALKER, MS*, S. POWERS, PhD, EdD* and M. K. STUART, EdD** \\ *Applied Physiology Laboratory, Louisiana State University, Baton Rouge, Louisiana, USA \\ **Human Performance Institute, Baton Rouge, Louisiana, USA
}

\begin{abstract}
The purpose of this investigation was to determine if a new proposed arm ergometer protocol was advantageous in eliciting higher peak oxygen uptake (peak $\mathrm{VO}_{2}$ ) when compared with two protocols currently referred to in the literature. Ten male subjects were tested on three different excercise protocols; a discontinuous test (DT), a continuous test (CT) and a new proposed jump-max test (JMT). The CT began at a work rate of 33 watts (W) $(40 \mathrm{rpm})$ with the power output (PO) being increased $16 \mathrm{~W}$ every 3 minutes. The DT began without resistance on the ergometer flywheel ( 50 rpm) and the work rate was increased by $25 \mathrm{~W}$ every 3 minutes with a 1 -minute rest between stages. The JMT began with a 3-minute pretest to determine a PO which elicited a HR of $120 \pm 5$ beat min $^{-1}$. After a 2-minute rest, subjects began exercise at the predetermined work rate $(80 \mathrm{rpm})$ with the PO being increased $20 \mathrm{~W}$ each minute of the test. Oxygen uptake was measured minute by minute via open circuit spirometry. Peak VO ${ }_{2}$ was higher $(p<0.05)$ in the JMT $\left(\bar{X} \pm S E M=2.36 \pm 0.061 . \mathrm{min}^{-1}\right)$ when compared with either $(\bar{X}$ $\left.\pm S E M=2.16 \pm 0.07 \mathrm{l} \cdot \mathrm{min}^{-1}\right)$ or the CT $\left(\bar{X} \pm \mathrm{SEM}=2.04 \pm 0.10 \mathrm{l} \cdot \mathrm{min}^{-1}\right)$. No difference $(p>0.05)$ existed in peak VO $\mathrm{O}_{2}$ between the CT and the DT. These data suggest that the proposed JMT may result in a higher measured peak $\mathrm{VO}_{2}$ in subjects when compared with either DT or CT of moderate to long duration.
\end{abstract}

Key words: Arm ergometry, Peak oxygen uptake, Incremental exercise.

\section{INTRODUCTION}

Interest in the physiological responses to arm work has grown over several years. Previous work has examined both the circulatory and metabolic response to arm exercise (Davies and Sargeant, 1974; Glaser et al, 1980; Sawka et al, 1980; Powers et al, 1984b), as well as the effects of work rate and speed on exercise efficiency (Powers et al, 1984a). In designing physiological experiments to study the acute or chronic effects of work using the upper body musculature, it is of interest to assess the peak oxygen uptake (peak $\mathrm{VO}_{2}$ ) during arm exercise. Surprisingly, given the extensive use of arm crank ergometry in both physiological and clinical research, little attention has focussed on the type of protocol employed to measure peak $\mathrm{VO}_{2}$ during arm exercise. At present, to our knowledge, only two studies have addressed the question of what is the optimal protocol for determination of $\mathrm{VO}_{2}$ peak during arm work (Washburn and Seals, 1983; Sawka et al, 1983).

Therefore, the purpose of this study was to determine if a new proposed arm crank ergometer (ACE) protocol was advantageous in eliciting a higher peak $\mathrm{VO}_{2}$ when compared with two protocols currently used in the literature.

\section{METHODS}

Ten male subjects, age (mean \pm SD) $21.8 \pm 5.8$ years and weight $77.8 \pm 12.7 \mathrm{~kg}$ volunteered to participate in this study. Prior to participation, subjects gave informed consent in accordance with the Louisiana State University Committee on human research. All subjects were trained aerobically but none were engaged regularly in training using the upper body.

Subjects reported to the laboratory at the same time of the day on three non-consecutive days. On each occasion, the subject performed one of three randomly assigned incremental protocols designed to determine peak $\mathrm{VO}_{2}$ for arm ergometry; a discontinuous test (DT), a continuous

Address for correspondence:

Dr. Scott K. Powers

School of HPERD

Louisiana State University

Baton Rouge

Louisiana, USA test, (CT) and a new proposed jump max test (JMT).

The CT used the protocol proposed by Shaw et al (1974). Briefly, the test began at a work rate of $33 \mathrm{~W}(40 \mathrm{rpm})$ with the power output (PO) being increased by $16 \mathrm{~W}$ every $3 \mathrm{~min}$. The test was terminated when the subject could not maintain the desired PO.

The DT required the subject to exercise $3 \mathrm{~min}$ while allowing a 1-min rest between stages as proposed by Schwade et al (1977). The test began with the subject cranking at a rate of $50 \mathrm{rpm}$ without resistance of the ergometer flywheel. The PO was increased $25 \mathrm{~W}$ every stage until the subject could no longer maintain the required work rate.

The JMT began with a 3-min incremental pretest to determine a work rate that would increase the subject's heart rate (HR) to $120 \pm 5$ beat. $\mathrm{min}^{-1}$. The pretest began at a work rate of $30 \mathrm{~W}(80 \mathrm{rpm})$ with the PO being increased $20 \mathrm{~W}$ every 30 seconds until the subject reached the target HR (i.e. $120 \pm 5$ beat. $\min ^{-1}$ ). If the subject reached the target HR prior to 3-min, the PO was reduced by $50 \%$ for the remainder of the pretest. Following the pretest, the subject was given a 2-min recovery period. The JMT began at the work rate that elicited the target HR of $120 \pm 5$ beat.min ${ }^{-1}$. Each stage of the JMT was $1-\mathrm{min}$ in duration with PO increments of $20 \mathrm{~W}(80 \mathrm{rpm})$.

Each test was performed on a Monark cycle ergometer mounted on a table. An adjustable seat was used to position the subject's shoulder at the height of the axis of rotation of the ergometer crankshaft and the arms were fully extended horizontally during cranking. Additionally, the legs were not braced and the feet were placed flat on the floor. Oxygen uptake $\left(\mathrm{VO}_{2}\right)$, carbon dioxide production $\left(\mathrm{VCO}_{2}\right)$ and expired ventilation $\left(V_{E}\right)$ were measured min-by-min via a Beckman Metabolic Measurement Cart which was calibrated prior to each experiment using standardised gases verified via gravimetric analysis. HR was determined over the last 15seconds of each work rate using electrocardiographic recordings.

The data were analysed using analysis of variance. A Duncan's multiple range test was used post-Hoc to determine where significant differences existed. Significance was established at the 0.05 level of confidence. 


\section{RESULTS AND DISCUSSION}

Mean values ( \pm SEM) for peak $\mathrm{VO}_{2}$, peak $H R$, peak $P O$, peak $V_{E}$, and total test time are contained in Table l. Note that the JMT differed from the $\mathrm{CT}$ in all the aforementioned variables. Further, the JMT differed from the DT in peak $\mathrm{VO}_{2}$, peak $\mathrm{PO}$ and total test time. Finally, the DT differed from the CT in only peak $P O$ and test time.

TABLE I

Comparison of peak oxygen uptake (peak VO), peak heart rate (HR), peak power output (peak PO), peak expired minute Ventilation $\left(V_{E}\right)$ during the last exercise stage, and total test time between the three arm ergometer test protocols. Values are means \pm SEM.

\begin{tabular}{lrrr}
\hline Variable & Jump max & Continuous & Discontinuous \\
\hline $\begin{array}{l}\text { Peak VO, } \\
\left(I . \mathrm{min}^{-1} \text { ) }\right.\end{array}$ & $2.36 \pm 0.06^{* *}$ & $2.04 \pm 0.10$ & $2.16 \pm 0.07$ \\
$\begin{array}{l}\text { Peak HR } \\
\text { (beat.min }\end{array}$ & $\left.177.00 \pm 4.00^{*}\right)$ & $161.00 \pm 6.00$ & $171.00 \pm 7.00$ \\
$\begin{array}{l}\text { Peak PO } \\
\text { (W) }\end{array}$ & $190.00 \pm 10.10^{* *}$ & $106.00 \pm 6.00$ & $130.00 \pm 7.20^{*}$ \\
$\begin{array}{l}\text { Peak VE } \\
\text { (I.min }\end{array}$ & $93.00 \pm 7.90^{*}$ ) & $73.00 \pm 5.90$ & $83.00 \pm 6.90$ \\
$\begin{array}{l}\text { Total test time } \\
\text { (min) }\end{array}$ & $6.00 \pm 0.30^{* *}$ & $12.50 \pm 0.90$ & $23.80 \pm 1.00^{*}$ \\
\hline
\end{tabular}

** $p<0.05$ different from both continuous and dicontinuous tests

${ }^{*} p<0.05$ different from continuous test

These data clearly support the idea that the new proposed JMT is preferred in many respects to the CT and DT. For example, the JMT yielded a significantly higher peak $\mathrm{VO}_{2}$ and peak $\mathrm{PO}$ when compared with either the CT or DT. Further, time required to complete the JMT was significantly shorter than that required to complete either the CT or DT.

Thus, these data support the idea that protocol selection to determine peak $\mathrm{VO}_{2}$ for $\mathrm{ACE}$ is particularly important. Recent evidence has suggested that peak $\mathrm{VO}_{2}$ during upper body exercise is probably limited by peripheral factors (i.e. local fatigue and muscle perfusion) rather than central circulatory factors (Glaser et al, 1980; Kamon and Pandolf, 1972; Magel et al, 1978). Therefore, it would seem that an incremental ACE test that reached peak power outputs rapidly could minimise the effects of local fatigue and thus elicit a higher peak $\mathrm{VO}_{2}$ than protocols that require a longer work period. This appeared to be the case in the present experiments.
In addition, peak $\mathrm{VO}_{2}$ values for arm work could also be affected by crank rate, as a slower cranking speed would necessitate development of greater muscular tension to perform the same PO (Sawka et al, 1983). At high levels of muscular tension, intramuscular pressure can exceed perfusion pressure (Petrofsky et al, 1981) and therefore decrease blood flow and limit oxygen uptake (Sawka et al, 1981; Sawka et al, 1983). The chosen crank rates for the CT and DT (40 and $50 \mathrm{rpm}$, respectively) were adapted directly from published literature (Shaw et al, 1974; Schwade et al, 1977). The decision to use $80 \mathrm{rpm}$ for the JMT was based on the aforementioned concept of minimising intramuscular pressure at a given PO and data by Powers et al (1984a).

In summary, we believe that the proposed JMT to determine peak $\mathrm{VO}_{2}$ during ACE offers advantages over previously published protocols in terms of time saving and the attainment of a higher peak $\mathrm{VO}_{2}$ and $\mathrm{PO}$.

\section{References}

Davies, C. T. M. and Sargeant, A. J., 1974 "Physiological responses to standardised arm work". Ergonomics 17: 41-49.

Glaser, R. M., Sawka, M. N., Brune, M. F. and Wilde, S. W., 1980 "Physiological responses to maximal effort wheelchair and arm crank ergometry". J.Appl.Physiol. 48: 1060-1064.

Kamon, E. and Pandolf, K. B., 1972 "Maximal aerobic power during laddermill climbing, uphill running, and cycling". J.Appl.Physiol. 32: 467-473.

Magel, J. R., McArdle, W. D., Toner, M. and Delio, D. J., 1978 "Metabolic cardiovascular adjustment to arm training". J.Appl.Physiol. 45: 75-79.

Petrofsky, J. S., Phillips, C. A., Sawka, M. N., Hanpeter, D. and Stafford, D. 1981 "Blood flow and metabolism during isometric contractions in cat skeletal muscle". J.Appl.Physiol. 50: 493-502.

Powers, S. K., Beadle, R. E. and Mangum, M., 1984a "Exercise efficiency during arm ergometry: effects of speed and work rate". J.Appl.Physiol. 56: 495-499.

Powers, S. K., Baker, B., Deason, R. and Mangum, M., 1984b “A trend analysis of steady state oxygen consumption during arm crank ergometry". J.Sports Med. 24: 131-134.

Sawka, M. N., Glaser, R. M., Wilde, S. W. and von Luhrte, T. C., 1980 "Metabolic and circulatory responses to wheelchair and arm crank exercise". J.Appl.Physiol. 49: 784-788.

Sawka, M. N., Petrofsky, J. S. and Phillips, C. A., 1981 "Energy cost of submaximal isometric contractions in cat fast and slow twitch muscles". Pfluegers Arch. 390: 164-168.

Sawka, M. N., Foley, M. E., Pimental, N. A., Toner, M. N. and Pandolf, K. B., 1983 "Determination of maximal aerobic power during upper body exercise". J.Appl.Physiol. 54: 113-117.

Schwade, J., Blomquist, C. G. and Shapiro, W., 1977 "A comparison of the response to arm and leg work in patients with ischemic heart diseae". Am. Heart J. 94: 203-208.

Shaw, D. F., Crawford, M. H., Karline, J. S., Di Donna, G., Carleton, R. M. Ross, J. and O'Rourke, R. A., 1974 "Arm crank ergometer: a new method for the evaluation of coronary artery disease". Am.J.Cardiol. 33: 801-805.

Washburn, R. A. and Seals, D. R., 1983 "Comparison of continuous and discontinuous protocols for the determination of peak oxygen uptake in arm cranking". Eur.J.Appl.Physiol. 51: 3-6. 